\title{
Painful scar neuropathy: principles of diagnosis and treatment
}

\author{
Pierluigi Tos ${ }^{1}$, Alessandro Crosio', Pierfrancesco Pugliese ${ }^{1}$, Roberto Adani², \\ Francesca Toia ${ }^{3}$, Stefano Artiaco ${ }^{1}$
}

${ }^{1}$ Department of Orthopedics, Reconstructive Microsurgery Unit, City of Health and Sciences of Turin, Trauma Hospital, 10100 Torino, Italy. ${ }^{2}$ Department of Hand Surgery and Microsurgery, University Hospital of Verona, 37126 Verona, Italy.

${ }^{3}$ Plastic and Reconstructive Surgery, Department of Surgical, Oncological and Oral Sciences, University of Palermo, 90127 Palermo, Italy.

Address for correspondence: Dr. Pierluigi Tos, Department of Orthopedics, Reconstructive Microsurgery Unit, City of Health and Sciences of Turin, Trauma Hospital, 10100 Torino, Italy. E-mail: pierluigi.tos@unito.it

\begin{abstract}
Nerve-tissue interactions are critical. Peripheral nerve injuries may involve intraneural and extraneural scar formation and affect nerve gliding planes, sometimes leading to complex clinical presentations. All of these pathological entities involve pain as the main clinical symptom and can be subsumed under the term "painful scar neuropathy". The authors review the literature on treatment approaches to peripheral nerve scar neuropathy and the outcomes of neurolysis-associated procedures and propose a simple classification and a therapeutic approach to scar neuropathy. The search retrieved twenty-one papers, twenty of which reported pain reduction or resolution with various techniques. There is no consensus on the best therapeutic approach to neuropathic pain due to scar tethering. Most authors report good or excellent results with different techniques, from nerve wrapping with anti-adhesion devices to nerve coverage or wrapping with vascularized tissue. The authors' classification of and therapeutic approach to peripheral nerve scar lesions aims at promoting a logical approach based on the analysis of lesion type (perineural, or endoneural and perineural), pain type (due to traction or external trauma, pain at rest), and number of previous operations. Patients need to be informed that multiple procedures may be required, that outcomes may be partial, and that surgery can potentially worsen preoperative conditions. The review found no evidence for the best therapeutic approach to scar neuropathy, but there is consensus on a multidisciplinary approach.
\end{abstract}

Key words:

Complex regional pain syndrome type II, painful neuropathy, painful scar neuropathy, scar neuritis, traction neuropathy

\section{INTRODUCTION}

Peripheral nerves have the ability to adapt to different positions during limb and joint movements. Such flexibility is enabled by a gliding apparatus around the

\begin{tabular}{|l|l|}
\hline \multicolumn{2}{|c|}{ Access this article online } \\
\hline Quick Response Code: & Website: \\
\hline & www.parjournal.net \\
\hline & \\
\hline & DOI: \\
\hline & $10.4103 / 2347-9264.160878$ \\
\hline
\end{tabular}

nerve that provides for elongation during movement. Small nutritional vessels entering the epineurium from surrounding muscles are among the principal connections between nerves and soft tissue.

A peripheral nerve subjected to elongation stress can extend a few millimeters compared to its length at rest. Elongation is enabled by a conjunctiva-like structure ${ }^{[1]}$ constituting the outermost layer of the nerve trunk that Millesi et al. ${ }^{[2]}$ designated paraneurium. The inner nerve structure can also undergo elongation, and gliding planes have been detected between deep epineurium and perineurium ${ }^{[3]}$ as well as between individual fascicles. Joint excursion, therefore, involves complete epineurial and intraneural movement, where nerve elongation 
compensates for the tension generated by movement and requires an intact gliding surface between the nerve and its surrounding tissue.

Clearly, the movement also stretches perineural and intraneural vascular structures, inducing vessel strain and reducing blood flow. A healthy gliding system prevents excessive stress from being exerted on vessel walls and ensures a sufficient blood supply to axons and Schwann cells. Preclinical studies have demonstrated that an $8 \%$ increase in nerve tension induces a $50 \%$ reduction in intraneural blood flow, whereas tension exceeding $15 \%$ of the baseline value induces an $80 \%$ reduction. ${ }^{[4]}$ In a study of rat sciatic nerves subjected to crush lesions, Boyd et al. ${ }^{[5]}$ documented nerve tension exceeding the intraneural microvessel compression threshold due to physiological movements, and found that it resulted in perineural scar formation and reduced intraneural vascularization.

Similarly, in the clinical settings formation of a perineural scar for any reason increases the tension on the nerve and may lead to prolonged ischemia. Wilgis and Murphy[6] described an association between reduced longitudinal gliding of the peripheral nerve and symptom recurrence following surgical decompression. In 1979, McLellan and Swash $^{[7]}$ reported that impaired linear gliding can induce a nerve lesion at a distance from the compression area, thus introducing the notion of traction neuropathy. The term indicates a condition related to impaired nerve gliding, whereas in Hunter 1991 description, ${ }^{[8]}$ it designates neurological symptoms due predominantly to the movement of the affected nerve. However, traction neuropathy may be too narrow a definition, given that some patients with extensive perineural fibrotic reactions experience constant pain both at rest and in the absence of movement. The condition is likely due to a fibrotic response that is, initially perineural and eventually becomes intraneural due to compression secondary to chronic scarring. Perineural fibrosis can induce ischemic stress in the involved fascicles, followed by degeneration of distressed axons, the repair process may subsequently lead to formation of an in-continuity neuroma with residual nerve function whose symptoms also involve pain at rest. ${ }^{|9|}$ Pain at rest may also be related to a perineural scar associated with intraneural scarring due to a traumatic Grade III or IV injury or to a Grade V lesion (nerve transection) according to Sunderland's classification. ${ }^{[10]}$ A painful neuroma at the suture site has been described in nearly $5 \%$ of repaired nerves. ${ }^{[11]}$ We, therefore, agree with Elliot ${ }^{[9]}$ that "traction neuropathy" is a somewhat limited definition, whereas "scarring neuritis" or "scar neuropathy" encompass all the conditions related to formation of perineural and intraneural fibrotic tissue involving neurological symptoms and induced by a nerve injury (intraoperative lesion, cut injury, stretching, or extrinsic compression due to fracture or hematoma). ${ }^{[12]}$

Based on our experience and the pathophysiology of nerve injuries, both fibrosis around a nerve (traction neuropathy) and inside/outside it (as in neuroma-in-continuity) can be classified as scarring neuritis/scar neuropathy, whose distinctive symptom is pain due to the pathological condition affecting the nerve.
End-neuromas, which are associated with similar symptoms, and neuromas-in-continuity without residual function, are not addressed in the present review, because their management is fairly well established: the former may benefit from relocation to deep, protected areas, whereas for the latter the initial treatment of choice is reconstruction with nerve grafts or conduits.

This review describes and discusses the main diagnostic and therapeutic approaches to neuropathic pain due to neuroma-in-continuity and peripheral nerve compression in scar tissue based on the literature and the authors' personal experience. The condition is complex and difficult to treat, and there is no consensus on the most appropriate surgical approach.

Different surgical procedures and products that limit scar formation and reduce pain are also reviewed, and a treatment algorithm based on the type of pain, lesion type, number of previous operations, and imaging data is proposed. Finally a review of the literature for treatment outcomes, with emphasis on the resolution of pain symptoms, is presented.

\section{EPIDEMIOLOGY}

Perineural scarring and consequently traction neuropathy have traditionally been considered to be complications of nerve decompression surgery. Nerve tethering in the surgical scar is still the main cause of symptoms related to perineural scarring. For instance, $7-20 \%$ of patients subjected to primary median nerve release report pain and symptom recurrence. ${ }^{[13]}$ The condition is difficult to manage, so much so that according to different reports compression symptoms persist after $40-90 \%$ of revision procedures, ${ }^{[14]}$ and $20 \%$ of patients actually require a third operation. ${ }^{[14]}$ Clinical failure rates of $25 \%$ have been reported after ulnar nerve release at the cubital tunnel, ${ }^{[15]}$ and a review of 50 studies found symptom recurrence in approximately $75 \%$ of treated patients. ${ }^{[16]}$ As noted above, $5 \%$ of nerve sutures have been estimated to induce a pain syndrome. ${ }^{[11]}$

However, the problem is not confined to peripheral nerves. Indeed, one of the most common complications of microdiscectomy and laminectomy, found in 15-20\% of patients, is failed back syndrome, which seems to be related to the formation of scars entrapping the released nerve roots. ${ }^{[17]}$ These patients often undergo additional procedures for the new symptoms.

Besides compression syndrome recurrence, neurogenic pain may be related to the formation of a neuroma-incontinuity associated with a partial lesion or severance of the peripheral nerve. This condition is found in $60-70 \%$ of traumatic injuries involving a peripheral nerve. ${ }^{[18]}$

\section{CLASSIFICATION OF SCARRING NEURITIS}

Millesi et al. ${ }^{[19]}$ have extensively investigated peripheral nerve gliding and devoted considerable effort to describing 
the role of the nerve-muscle tissue interface in normal nerve function.

Millesi et al. ${ }^{[19]}$ vast surgical experience with peripheral neurolysis led to the publication of a seminal paper describing a new anatomo-surgical classification of perineural and intraneural scar lesions. The classification is a useful approach to perineural and intraneural scar injury because it couples each subgroup of fibrotic lesions to specific types of surgical neurolysis based on scar severity. However, although intraneural lesions are described in excessive detail, the clinical outcomes do not seem to correlate with preoperative pain measurement.

Here we describe a simplification of Millesi et al. ${ }^{[19]}$ original classification and propose an approach that, by correlating the pathological findings to clinical and imaging data, has the potential to improve surgical treatment. The revised classification encompasses two injury types, extraneural and intraneural/extraneural scar lesions, based on the perineural tissue changes that impair nerve gliding and the intraneural problems that give rise to pain and hypersensitivity. Type I injuries are related to compression due to causes such as prior surgery, hematoma, and bone fragments, with involvement of the gliding surface (conjunctiva-nervorum) and formation of extensive scar tissue around the nerve, as depicted in Figure 1. These lesions are generally amenable to simple external neurolysis, with additional surgical procedures as required to avoid recurrence of perineural fibrosis (i.e. restoration of the gliding plane by anti-adhesion gel, vein conduit or other wrapping material). Pain is often related to joint movement and is less frequent at rest. On ultrasound (US) examination, the nerve has a normal fascicle structure. Type II injuries affect the entire nerve structure, from the epineurium to the endoneurium, and are usually secondary to significant nerve trauma such as a partial lesion or a transection of the nerve trunk treated by neurorrhaphy (neuroma-in-continuity). These injuries require procedures that may involve nerve fascicles and the epineurium, from epineurectomy and epineurotomy up to partial resection and grafting as described by Millesi et al. ${ }^{[19]}$ In type II lesions additional surgical procedures are directed not only at avoiding recurrence of perineural fibrosis, but also at protecting the nerve

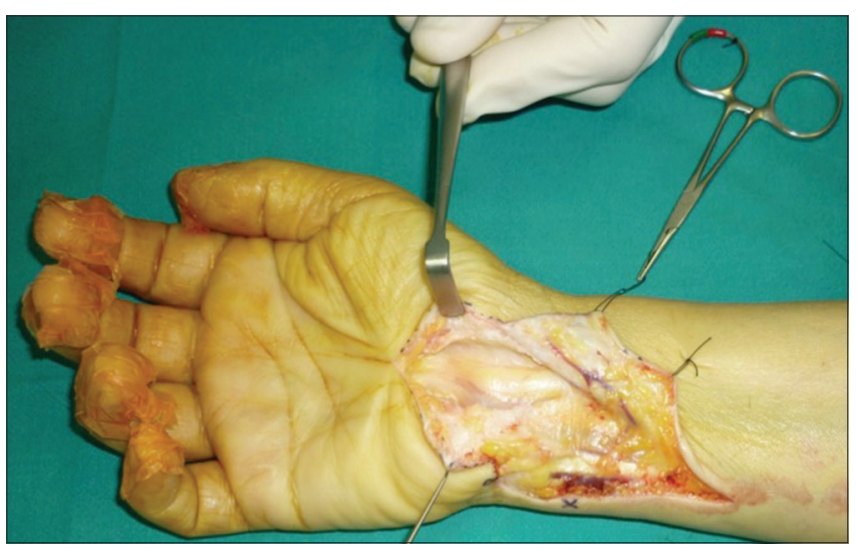

Figure 1: Median nerve entrapped in scar tissue against external mechanical insults. Outcomes are less predictable than in type I lesions. Pain at rest is common and is exacerbated by external trauma. US examination provides useful information on the intraneural pathology.

Type II lesions, with the exception of partial lesions due to a laceration or the sequelae of a nerve suture, correspond to Sunderland's third-degree lesions, which from the pathological standpoint include painful neuromain-continuity with residual function, one of the most challenging therapeutic problems. Fourth- and fifth-degree lesions are outside the scope of this review, as they lack residual nerve function and are managed by resection and reconstruction.

\section{CLINICAL SYMPTOMS AND SIGNS}

Patients typically report pain of four types, as described by Elliot ${ }^{[9]}$ : spontaneous pain, pressure pain, movement pain, and hypersensitivity or unpleasant skin sensation to light touch, including hyperesthesia, hyperpathia, and allodynia.

The causal association is most obvious for pressure pain and movement pain elicited by the motion of adjacent tendons and joints. At present, hypersensitivity usually involves the skin overlying the affected nerve portion. The most poorly understood and unpleasant of these pain types is spontaneous pain, which is found in the majority of patients; it is most often a continuous or basal pain with spikes of increased intensity, or spiking pain that is often severe, has a variable frequency, and may be associated with reflex motor activity, example, jerking of the entire upper limb. ${ }^{[9]}$

These symptoms, presenting singly or combined, are compounded by complex regional pain syndrome type II (CRPS II) or causalgia, ${ }^{[20,21]}$ due to fiber disorganization within the neuroma-in-continuity. Typical CRPS II features are onset after a nerve injury and continuous pain or allodynia-hyperalgesia that is usually, but not invariably confined to the territory of the injured nerve. Edema, skin blood flow abnormalities, or abnormal sudomotor activity may be detected in the area affected by pain since the time of injury. Timely management appears to be critical. ${ }^{[22]}$

\section{DIAGNOSIS}

History is crucial to establish the cause of symptoms, be it related to simple nerve decompression, reconstruction, direct trauma, or posttraumatic scarring.

Physical examination and pain type, at rest or elicited by movement or mechanical stimuli, may provide information on the lesion type. Pain at rest commonly entails that the scar involves the deep nerve structure. Perineural scarring usually induces nerve tethering, which is exacerbated by movement, that is, a loss of peripheral nerve gliding. Tinel's sign is invariably positive, and the patient often has hyperalgesia and/or allodynia in the territory of the involved nerve. ${ }^{[9,23]}$ 
As regards diagnostic imaging, US provides reliable information on the actual extent of the nerve injury (due for instance to a previous procedure), the amount of scarring, and the state of the outer and inner connective tissue layers of the nerve trunk. It thus provides an indication for surgery by demonstrating, before the operation, the various degrees of scarring described by Millesi et al. ${ }^{[19]}$

Moreover, according to a paper of the European Society of Musculoskeletal Radiology, musculoskeletal US seems to be the imaging technique of choice for peripheral nerve structure evaluation. ${ }^{[24]}$

Most studies use US to investigate the intraneural structures and changes due to chronic compression or trauma. ${ }^{[25]}$ In these patients, US has proven to be even more effective than electrophysiological tests in depicting intraneural distress. ${ }^{[25]}$ Some studies compare US findings, including signs of edema, loss of echogenicity, and fascicular echostructure before and after tunnel syndrome surgery. ${ }^{[26]}$

Padua et al. ${ }^{[27]}$ group has advanced an interesting proposal that agrees with our classification of scar lesions, highlighting that valuable US features include depiction of very small nerves and dynamic imaging, which can document how the nerve interacts with surrounding tissue. Indeed, key diagnostic features of scarring neuropathy are an assessment of the nerve's relationships with surrounding tissue and depiction of any gliding impairment.

A critical advantage of US is that it affords direct visualization of the nerve injury, thus providing information on its cause and enabling treatment selection. ${ }^{[27]}$ We thus feel that US scanning of the nerve and surrounding tissue entails a dual benefit for both patient and surgeon: it identifies the site of the nerve injury and depicts its relationships with scar tissue, documenting any obstacles to gliding. Combining anatomo-sonographic findings, electromyography data, and clinical information can help the surgeon select the most appropriate treatment approach.

Magnetic resonance imaging (MRI) enhances diagnosis and surgical planning; conventional MRI may depict indirect signs of nerve damage such as edema whereas high-resolution MRI provides direct visualization of injured and scar-tethered nerves, including the smaller peripheral branches. ${ }^{[28,29]}$

In experienced hands, MRI and US can provide crucial information in preoperative planning of revision nerve release surgery by documenting residual or recurrent pathology or the sequelae of previous surgery.

Electromyography examination is also important because it documents the degree of peripheral nerve distress, and findings can be compared over time (preoperative, postoperative, follow-up examination).

However, it is still unclear why similar pathological conditions induce pain in some patients but are painless in others, including patients with in-continuity neuromas and end-neuromas.

\section{SURGICAL OPTIONS}

Surgical exploration, neurolysis under magnification, and procedures aimed at preventing new scar formation such as flap coverage and application of anti-adhesion devices must be preceded by appropriate medical treatment and pharmacological and physical therapy with dedicated operators for at least six months. Although there is no consensus on surgery timing, ${ }^{[30]}$ surgery is generally indicated when medical and physical therapy have failed to bring benefit.

Some authors have achieved pain reduction in a large number of patients using pulsed radiofrequency before surgery or following a recurrence. ${ }^{[31]}$

Surgical treatment of these conditions begins with neurolysis. External neurolysis is performed in cases with external compression, to free the nerve from the extrinsic compression. This may involve either accessing only the epineurium (epineurotomy) or removing part or all of it (partial or total epineurectomy) as shown in Figure 2a. Only in very selected cases is internal neurolysis performed, to treat an intraoperative iatrogenic injury or postoperative scar recurrence between fascicles. The procedure begins with identification of the normal proximal and distal nerve portions; the nerve is then mobilized above and below the injury site and its course toward the injury site is carefully dissected free of external scarring, points of tethering, or abnormalities.

The second step involves the relocation of the nerve tract involved by neurolysis to a "soft" vascularized bed enabling gliding. ${ }^{[30]}$ Other procedures use vascularized or nonvascularized autologous tissue or an anti-adhesion gel. However, anti-adhesion devices, flaps, or other autologous tissues are not unequivocally recommended.

Here we propose a management strategy of posttraumatic scar lesions based on two mainstays, including (1) lesion categorization into extraneural and intraneural as described above, and (2) clinical information in terms of pain symptoms.

A combination of history data and US findings, which document the intraneural injury in a very early phase, supplies critical work-up information and provides an indication for external neurolysis versus a more extensive

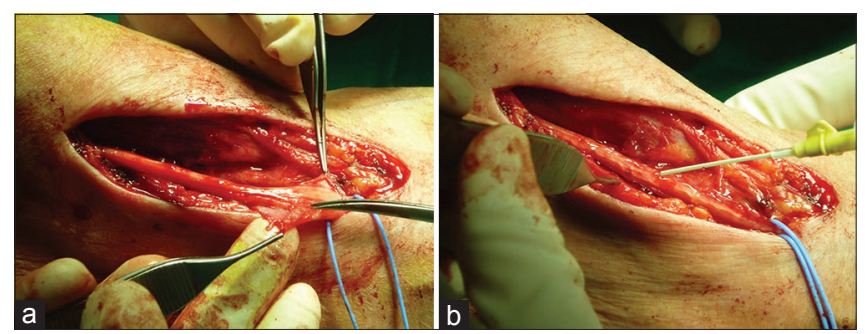

Figure 2: (a) External neurolysis and epineurectomy on median nerve at the elbow; (b) application of carboxy-methylcellulose/ phosphatidylethanolamine gel on median nerve after neurolysis 
neurolysis involving the epineurium and if necessary the perineurium.

Another key factor is the number of previous operations, simple external neurolysis is indicated after the first recurrence while a vascularized flap with a more extensive neurolysis is indicated following multiple failed surgical treatments.

Type I injuries, where scar tissue hampers gliding, should be managed by external neurolysis if the intraneural echostructure is normal, anti-adhesion gel, vein-wrapping, or thin flap coverage may be sufficient.

In type II lesions (neuromas-in-continuity), where US depicts a lack of structural homogeneity inside the nerve, more extensive neurolysis may be required, with epineurectomy and rarely, internal neurolysis under magnification. These patients also require deep nerve transposition, coverage with thick vascularized flaps, and restoration of a suitable gliding bed.

Patients with continuous pain due to an earlier traumatic injury to superficial nerves triggered by external stimuli, and those undergoing revision of a failed prior revision procedure, require deep nerve transposition and coverage with thick vascularized flaps providing both biological and mass effects. ${ }^{[32]}$

Relevant clinical data, including pain type (due to external compression, continuous, or movement-related) and cause of the lesion, can indicate the most appropriate management strategy. Patients with pain due to direct trauma may benefit from the bulk effect of a flap or from nerve relocation to a deep, protected area, whereas simple neurolysis with application of anti-adhesion devices is preferable in simple traction neuropathy, where pain is more often secondary to external traction.

Early active movement after surgery is indicated to prevent adhesion recurrence.

The next section describes the main techniques used in the treatment of scarring neuropathy and painful neuroma-in-continuity with residual nerve function after neurolysis.

\section{SURGICAL MANAGEMENT AFTER NEUROLYSIS}

\section{Commercial gels and anti-adhesion devices}

These devices are used to restore the lost gliding surface. Since 1970, when intraperitoneal anti-adhesion devices were first introduced, a number of products characterized by different shapes and chemical compositions have been developed to limit perineural scar formation. Gels developed specifically for peripheral nerve-tissue began to be produced in 2000. Early anti-adhesion gels were based on collagen-dextran (ADCON-T/N) and were initially used in spinal surgery. Preclinical application to rat peripheral nerve achieved a satisfactory reduction of perineural scarring. These gels were, however, abandoned after reports of wound dehiscence and dural fistula formation. ${ }^{[33]}$
Products based on hyaluronic acid (HA) have proved to be more effective. Initial preclinical studies have documented their anti-adhesion properties and safety. ${ }^{[3]}$ $\mathrm{HA}$ is marketed alone as Hyaloglide $\mathrm{e}^{(\mathrm{R})[35]}$ or associated to carboxy-methylcellulose (CMC, Seprafilm $\left.{ }^{(\mathrm{R})}\right) \mathrm{.}^{[36]}$

However, there is no consensus on the actual effect of anti-adhesion devices. According to some researchers they reduce collagen deposition by interfering with granulocyte diapedesis and blocking the synthesis of interleukin-1, which is crucial for fibroblast activation, ${ }^{[37]}$ whereas others deny an effect on cytokines and admit only to a physical barrier action. ${ }^{[38]}$

CMC has subsequently been associated with other molecules, including phosphatidylethanolamine a nonionic molecule whose tensioactive properties provide tissue lubrication and a mechanical barrier to restore gliding. ${ }^{[39]}$ CMC-PE has also been shown to reduce perineural adhesions; it is already available on the market and has proven to be highly effective in preventing the formation of abdominal, spinal and tendon adhesions. ${ }^{[40]}$

In 2005, another macromolecule, polyethylene glycol oxyde (PEO), was associated with $\mathrm{CMC}$ to enhance its anti-adhesion effect. Preclinical studies have documented its ability to reduce protein, hence collagen, deposition on tissue. ${ }^{[40,41]}$ However, there is no conclusive evidence for its effectiveness in the peripheral nervous system. A single paper has demonstrated its safety and effectiveness in an animal model (Tos et al., paper submitted). A representative image of gel application after neurolysis is shown in Figure 2b.

Collagen-based products have recently been developed for wrapping around injured nerves. ${ }^{[42,43]}$ These products are theorized to form a microenvironment within the compressed nerve, which keeps nerve growth factors within the epineurium to enhance nerve gliding, and which are subsequently slowly absorbed.

A recent study of a small sample with a short follow-up describes a novel nerve-wrapping technique for the upper extremities using a type I collagen conduit wrap. Its effectiveness is similar to that of other anti-adhesion devices, but it entails a lower fewer risk of complications compared to wrapping the nerve in autologous tissue such as vein (Neura Wrap; Integra LifeSciences, Plainsboro, NJ, USA). ${ }^{[3]}$

There are therefore several different types of anti-adhesion devices, but scant information as to which is the most effective at the clinical and preclinical level, even though all seem to limit perineural scarring formation without any particular side effects. A major advantage is their fast application and less invasive surgical dissection, without the need for further procedures (and possible attendant injury), which considerably reduces operating time compared to the surgical approaches described above. ${ }^{[34]}$ Notably, there are no clinical trials comparing the effectiveness of the two approaches. A recent case review has advanced the proposal to apply anti-adhesion devices in cases where the nerve, released from the scar, appears 
healthy or only moderately injured, and to use local or free flaps for clearly distressed nerves in the presence of a strong inflammatory reaction. ${ }^{[44]}$

\section{Vein conduits}

Masaer et al. ${ }^{[45]}$ was the first to describe nerve-wrapping in an "opened" vein segment, which provided satisfactory results both in terms of sensitivity improvement and of reduction of recurrences. ${ }^{[46]}$ Elliot $^{[9]}$ reported poor outcomes in neuromas-in-continuity of the palm and the fingers, describing pain recurrence at the site of treatment due especially to repeated trauma, because the thin vein wall does not adequately protect the nerve against external insults.

Some authors suggest covering sutures with a vein, as earlier for collagen-gel, to prevent end-neuroma formation at direct suture sites. ${ }^{[47]}$

\section{Flaps}

A variety of flaps, pedicled (local) or free, are used for coverage after neurolysis: synovial, fascial, adipofascial, muscle and skin with subcutaneous tissue flaps.

Compared to vein wraps, gels, and other anti-adhesion devices, flaps have a dual function: to envelop the injured nerve in a highly vascularized tissue to maximize nutrient supply, and to provide a bulk effect, for example, protection against external mechanical insults. This approach is often used in patients in whom revision surgery has had poor outcomes or when the quality of local tissue does not allow a simpler procedure.

Typical local flaps raised in patients with recurrences or sequelae of carpal tunnel syndrome (CTS) include the hypothenar fat pad flap first described by $\mathrm{Cramer}^{[48]}$ and improved by Strickland, and the palmaris brevis flap described by Rose et al. ${ }^{[49]}$ Their main advantage is that they provide a buffer of highly vascularized adipofascial or muscle tissue above the treated nerve. The synovial flap from the flexor tendons described by Wulle is still a very good option for recalcitrant CTS..$^{[50]}$

Thicker flaps can be raised from the volar forearm: the dorsal ulnar artery adipofascial flap described by Becker and Gilbert ${ }^{[51]}$ can be used as an adipofascial flap to wrap the nerve [Figure $3 a$ and $b$ ] or as a fasciocutaneous flap to provide greater protection, the adipofascial radial artery perforator flap ${ }^{[32]}$ and the adipofascial variant of the posterior interosseous flap raised from the dorsal portion of the forearm ${ }^{[52]}$ can be employed in the same way; and the pronator quadratus muscle flap ${ }^{[53]}$ may be a useful solution when the injury is proximal to the wrist.

Numerous free vascularized flaps, described for coverage of freed nerves, are however, rarely used. The free omental flap, ${ }^{[54]}$ lateral arm flap, scapular flap, and groin flap $^{[44]}$ seem to be more effective than local flaps, yet the approach is recommended only for use in patients with severe conditions who have already been treated and in those with hand and forearm lesions where a local flap would impair hand use. Yamamoto et al. ${ }^{[20]}$ have gone further, and they raised an anterolateral vascularized thigh flap that included the lateral cutaneous nerve of the thigh

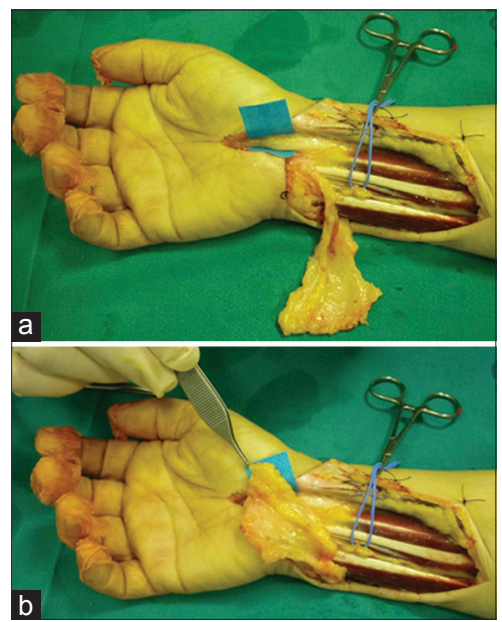

Figure 3: (a) Adipofascial dorsoulnar Becker flap covering and wrapping a median nerve; (b) the bulk effect of the flap protects the nerve from external trauma

to reconstruct the median nerve, and described early pain resolution and full recovery of wrist and hand mobility five months from the procedure. We recommend such complex procedures only in patients with severe nerve injury and failure of multiple surgical procedures, where another local flap could result in local tissue damage.

\section{Pain neuromodulation}

Multiple surgical failures may provide an indication for direct peripheral nerve stimulation, to relieve chronic pain through preferential activation of myelinated fibers, inducing long-term depression of synaptic efficacy. ${ }^{[55,56]}$

Spinal cord stimulation, which is applied more often to treat CRPS I, may also be beneficial..$^{[57]}$

\section{SCAR NEURITIS AND OUTCOMES: LITERATURE REVIEW}

PubMed was reviewed for papers reporting treatment approaches and patient outcomes of scar neuritis and neuropathic pain, in particular studies of recurrent median and ulnar nerve compression, postsurgical fibrosis of lower and upper limb nerves, CRPS II, and application of HA acid and gels that also described pre- and post-operative pain assessment by the visual analogue scale (VAS) or numerical rating scale. Case reports and animal studies were excluded. Papers were sorted by the treatment approach to neurolysis.

Overall, 21 papers were retrieved; the majority described the treatment of median and ulnar nerve entrapment recurrence. The method most frequently associated with neurolysis was flap coverage (15 articles); the remaining papers described the use of anti-adhesion devices (3 articles) to reduce pain and prevent recurrences, and vein wraps (3 articles).

All approaches provided good outcomes, although most studies involved small samples, from 4 patients to 65 patients. All methods achieved a postoperative reduction of at least four VAS points. All but one study described complete or satisfactory pain reduction. These 
data are summarized in Table 1 . No alternative options are mentioned for patients reporting no improvement.

Despite published reports of highly satisfactory outcomes and success rates close to $100 \%$ with a range of techniques, clinical practice demonstrates that such conditions are difficult to treat and at times are only partially solved.

There is scant published evidence regarding the diagnostic work-up and treatment of scar neuropathy. Patients should be warned that their condition is not easy to address and that surgical treatment may have to be followed by a more aggressive approach if symptoms persist.

Patients with pain due to nerve entrapment in scar tissue require careful evaluation through history, assessment of pain type, and accurate US scanning, to establish the site of the scar tissue injury and whether the nerve contains internal damage. In patients for whom surgery will be straightforward local tissues provide a suitable bed, barrier devices may be applied first to attempt to treat the problem by a less invasive approach. Patients subjected to multiple procedures due to recurrences and those with a severely injured gliding bed require more extensive neurolysis and coverage with a local or free vascularized flap.
If symptoms are due exclusively to external trauma and the patient has pain at rest, wraps or thick adipofascial flaps are the treatment of choice to avoid external trauma and protect the nerve. If the lesion is external to the nerve and pain is due to scar tethering the prognosis is more favorable and the risk of recurrence lower, whereas pain due to intraneural injury is more difficult to treat because the outcome of internal neurolysis is unpredictable and may itself induce formation of even worse scarring.

Data on the timing of a recurrence varies widely, from twenty days to thirty days to months, the mechanism of recurrence is also unclear.

Helping patients with these conditions requires a multidisciplinary approach and close collaboration of the surgeon, pain clinician, physiotherapist, and psychologist, because for reasons that are still unclear the patient is often the very cause of the problem. The risk of persistent or even worsening pain symptoms should be clearly stated prior to surgery, as any intervention may induce symptom worsening in patients with complex pain syndromes.

If the pain is not alleviated following the initial procedure, subsequent operations are unlikely to be successful, and further attempts may involve diminishing returns. ${ }^{[30,76]}$

Table 1: List of the 21 papers describing peripheral nerve neurolysis, associated procedures, and pain outcomes retrieved by the PubMed search, sorted by the technique used for neurolysis

\begin{tabular}{|c|c|c|c|}
\hline Author & Surgical approach & Nerve & $\begin{array}{l}\text { Pain alleviation. Number of patients and } \\
\text { percentage }(\%) \text { of pain reduction }\end{array}$ \\
\hline Reisman and Dellon ${ }^{[58]}$ & Abductor digiti minimi & Median & Pain reduction in 11/12 patients (91) \\
\hline Strickland et al. ${ }^{[59]}$ & Hypothenar fat pad flap & Median & $\begin{array}{l}\text { Excellent results in alleviating recalcitrant idiopathic } \\
\text { CTS (95 satisfaction in } 62 \text { patients) }\end{array}$ \\
\hline $\operatorname{Rose}^{[60]}$ & Palmaris brevis muscle flap & Median & Complete pain relief in all patients (13 hands) (100) \\
\hline Jones $^{[61]}$ & Pedicled or free flaps & Median/ulnar & Pain reduction in $7 / 9$ patients $(78)$ \\
\hline Giunta et al.[62] & Hypothenar fat pad flap & Median & Pain reduction in $8 / 9$ patients (89) \\
\hline Frank et al. ${ }^{[63]}$ & Hypothenar fat pad flap & Median & Pain reduction in $8 / 9$ patients $(89)$ \\
\hline Guillemot et al. ${ }^{[64]}$ & Fat graft & Median & No pain reduction in 4 patients \\
\hline Mathoulin et al. ${ }^{[65]}$ & Hypothenar fat pad flap & Median & Pain resolution in $41 / 45$ patients (98) \\
\hline $\begin{array}{l}\text { De Smet and } \\
\text { Vandeputte }\end{array}$ & Hypothenar/ulnar fat pad flap & Median & Pain reduction in $9 / 14$ patients $(64)$ \\
\hline Dahlin et al. ${ }^{[67]}$ & $\begin{array}{l}\text { Pedicled ulnar, dorsal forearm flaps } \\
\text { Free groin, scapular, lateral arm flaps }\end{array}$ & Median & Pain reduction in $10 / 14$ patients $(71)$ \\
\hline Goitz and Steichen ${ }^{[54]}$ & Free omental flaps & Median & Pain reduction in $7 / 11$ patients $(63)$ \\
\hline Luchetti et al. ${ }^{[68]}$ & $\begin{array}{l}\text { Fascial and fasciocutaneous island } \\
\text { flaps (hypothenar fat pad, forearm radial } \\
\text { artery, forearm ulnar artery, ulnar fascial } \\
\text { fat, and posterior interosseous) }\end{array}$ & Median & $\begin{array}{l}\text { Four point VAS score reduction in } \\
23 / 25 \text { patients }(92)\end{array}$ \\
\hline Craft et al. ${ }^{[69]}$ & Hypothenar fat pad flap & Median & Pain resolution in $83 \%$ of 28 patients \\
\hline Fusetti et al. ${ }^{[70]}$ & Hypothenar fat pad flap & Median & Pain reduction in $18 / 20$ patients $(90)$ \\
\hline Elliot et al. ${ }^{[71]}$ & Vascularized forearm fascial flap & Median/ulnar & Pain resolution in $8 / 14$ patients $(57)$ \\
\hline Soltani et al. ${ }^{[43]}$ & Collagen: neurolysis + collagen wrap & Median/ulnar & $\begin{array}{l}\text { Resolution/improvement in } 4 \text { patients (median) } \\
\text { Resolution in } 3 / 4 \text { patients (cubital tunnel syndrome) }\end{array}$ \\
\hline Espinoza et al. ${ }^{[72]}$ & Microneurolysis alone versus ADCON/TN & Median/ulnar & Pain reduction in $80 \%$ of 54 patients \\
\hline Atzei et al..[35] & $\begin{array}{l}\text { Neurolysis or nerve repair with } \\
\text { Hyaloglide }^{(R)}\end{array}$ & Hand nerves & $\begin{array}{l}\text { Pain reduction quicker with Hyaloglide }{ }^{(R)} \\
14 \text { patients treated with HA versus } 16 \text { treated } \\
\text { without gel }\end{array}$ \\
\hline Varitimidis et al. ${ }^{[73]}$ & Autologous vein & Median & Pain reduction in $14 / 15$ patients $(93)$ \\
\hline Masear ${ }^{[74]}$ & Vein: autologous+allograft & $\begin{array}{l}\text { Median } \\
\text { and various } \\
\text { peripheral nerves }\end{array}$ & $\begin{array}{l}\text { Good/excellent results in } 94 / 119 \text { patients ( } 79) \text {; no } \\
\text { pain relief in } 9 / 119 \text { patients }\end{array}$ \\
\hline Kokkalis et al. ${ }^{[75]}$ & Vein wrap & Ulnar & Pain reduction in $100 \%$ of 17 patients \\
\hline
\end{tabular}




\section{FUTURE DIRECTIONS}

Overall, the diagnosis and treatment of scar neuritis and neuropathic pain still present significant problem areas. A clear lesion classification correlating injury with the clinical problem and convincing evidence of the effectiveness of one treatment above the others would improve both diagnosis and clinical outcomes.

Despite active clinical research, no gold standard treatment has been established, as no medical or surgical treatment has shown superiority over the others with regards to the rate and extent of clinical response. No treatment among the myriad that have been described assures an effective and/or reliable outcome, and the same treatment can lead to very different outcomes in different patients, from complete resolution to a worsening of symptoms. Currently, neither surgeons nor pain therapists are able to predict, which patient will respond to treatment and for what duration that response may last.

All these data suggest that the key for improving our approach to neuropathic pain lies in gaining better insight into its underlying mechanisms. A genetic predisposition is likely to exist, and individual differences in biochemical signals involved in nerve pain and their possible modulation for therapeutic purposes deserves further study.

Then, we foresee genetic and biomolecular research as promising fields of future investigation, which could ultimately lead to a better understanding and management of painful scar neuropathy.

\section{REFERENCES}

I. Lang J. On connective tissue and blood vessels of the nerves. Z Anat Entwicklungsgesch 1962; 123:61-79.

2. Millesi H, Zoch G, Reihsner R. Mechanical properties of peripheral nerves. Clin Orthop Relat Res 1995;314:76-83.

3. Sunderland S, Bradley K. Stress-strain phenomena in denervated peripheral nerve trunks. Brain 1961;84:125-7.

4. Clark WL, Trumble TE, Swiontkowski MF, Tencer AF. Nerve tension and blood flow in a rat model of immediate and delayed repairs. J Hand Surg Am 1992; 17:677-87.

5. Boyd BS, Puttlitz C, Gan J, Topp KS. Strain and excursion in the rat sciatic nerve during a modified straight leg raise are altered after traumatic nerve injury. J Orthop Res 2005;23:764-70.

6. Wilgis EF, Murphy R. The significance of longitudinal excursion in peripheral nerves. Hand Clin 1986;2:76I-6.

7. McLellan DL, Swash M. Longitudinal sliding of the median nerve during movements of the upper limb. J Neurol Neurosurg Psychiatry 1976;39:566-70.

8. Hunter JM. Recurrent carpal tunnel syndrome, epineural fibrous fixation, and traction neuropathy. Hand Clin 1991;7:491-504.

9. Elliot D. Surgical management of painful peripheral nerves. Clin Plast Surg 20|4;41:589-6/3.

10. Sunderland S. Nerve Injuries and Their Repair: A Critical Appraisal. 3rd ed. London: Churchill Livingstone; 1991.

II. Sunderland S. Nerves and Nerve Injury. 2nd ed. London: Churchill Livingstone; 1978.

12. Ide C. Peripheral nerve regeneration. Neurosci Res 1996;25:101-2I.

13. Jones NF, Ahn HC, Eo S. Revision surgery for persistent and recurrent carpal tunnel syndrome and for failed carpal tunnel release. Plast Reconstr Surg 2012;129:683-92.

14. Amadio PC. Interventions for recurrent/persistent carpal tunnel syndrome after carpal tunnel release. J Hand Surg Am 2009;34:1320-2.

15. Lowe JB 3rd, Mackinnon SE. Management of secondary cubital tunnel syndrome. Plast Reconstr Surg 2004; I I3:EI-16.
16. Antoniadis G, Richter HP. Pain after surgery for ulnar neuropathy at the elbow: a continuing challenge. Neurosurgery 1997;41:585-9.

17. Fransen P. Reduction of postoperative pain after lumbar microdiscectomy with DuraSeal Xact Adhesion Barrier and Sealant System. Spine J 20I0;10:75I-6I.

18. Mavrogenis AF, Pavlakis K, Stamatoukou A, Papagelopoulos PJ, Theoharis S, Zoubos AB, Zhang Z, Soucacos PN. Current treatment concepts for neuroma-in-continuity. Injury 2008;39 Suppl 3:S43-8.

19. Millesi H, Rath TH, Reihsner R, Zoch G. Microsurgical neurolysis: its anatomical and physiological basis and its classification. Microsurgery 1993; 14:430-9.

20. Yamamoto T, Narushima M, Yoshimatsu H, Yamamoto N, Mihara M, Koshima I. Free anterolateral thigh flap with vascularized lateral femoral cutaneous nerve for the treatment of neuroma-in-continuity and recurrent carpal tunnel syndrome after carpal tunnel release. Microsurgery 2014;34:I45-8.

21. Mackinnon SE. Evaluation and treatment of the painful neuroma. Tech Hand Up Extrem Surg 1997; 1:195-212.

22. Carroll I, Curtin CM. Management of chronic pain following nerve injuries/ crps type II. Hand Clin 20I3;29:40I-8.

23. Davis EN, Chung KC. The Tinel sign: a historical perspective. Plast Reconstr Surg 2004; I 14:494-9.

24. Klauser AS, Tagliafico A, Allen GM, Boutry N, Campbell R, Court-Payen M, Grainger A, Guerini H, McNally E, O’Connor PJ, Ostlere S, Petroons P, Reijnierse M, Sconfienza LM, Silvestri E, Wilson DJ, Martinoli C. Clinical indications for musculoskeletal ultrasound: a Delphi-based consensus paper of the European Society of Musculoskeletal Radiology. Eur Radiol 2012;22: I 40-8.

25. Wang Y, Zhao C, Passe SM, Filius A, Thoreson AR, An KN, Amadio PC. Transverse ultrasound assessment of median nerve deformation and displacement in the human carpal tunnel during wrist movements. Ultrasound Med Biol 2014;40:53-6I.

26. Kerasnoudis A. Which ultrasound method has the upper hand in the follow-up of the patients with recurrent carpal tunnel syndrome? Ann Rheum Dis 2013;72:ell.

27. Padua L, Di Pasquale A, Liotta G, Granata G, Pazzaglia C, Erra C, Briani C, Coraci D, De Franco P, Antonini G, Martinoli C. Ultrasound as a useful tool in the diagnosis and management of traumatic nerve lesions. Clin Neurophysiol 2013; 124:1237-43.

28. Andreisek G, Burg D, Studer A, Weishaupt D. Upper extremity peripheral neuropathies: role and impact of MR imaging on patient management. Eur Radiol 2008; 18:1953-61.

29. Thawait SK, Wang K, Subhawong TK, Williams EH, Hashemi SS, Machado AJ, Thawait GK, Soldatos T, Carrino JA, Chhabra A. Peripheral nerve surgery: the role of high-resolution MR neurography. AJNR Am J Neuroradiol 2012;33:203-10.

30. Lipinski LJ, Spinner RJ. Neurolysis, neurectomy, and nerve repair/ reconstruction for chronic pain. Neurosurg Clin N Am 20 I4;25:777-87.

3I. Haider N, Mekasha D, Chiravuri S, Wasserman R. Pulsed radiofrequency of the median nerve under ultrasound guidance. Pain Physician 2007; 10:765-70.

32. Adani R, Tos P, Tarallo L, Corain M. Treatment of painful median nerve neuromas with radial and ulnar artery perforator adipofascial flaps. J Hand Surg Am 2014;39:721-7.

33. Hieb LD, Steves LD. Spontaneous postoperative cerebrospinal fluid leaks following application of anti-adhesion barrier gel: case report and review of the literature. Spine 200I;26:748-5I.

34. Burns JW, Skinner K, Colt MJ, Burgess L, Rose R, Diamond MP. A hyaluronate based gel for the prevention of postsurgical adhesions: evaluation in two animal species. Fertil Steril 1996;66:8I4-2I.

35. Atzei A, Calcagni M, Breda B, Fasolo G, Pajardi G, Cugola L. Clinical evaluation of a hyaluronan-based gel following microsurgical reconstruction of peripheral nerves of the hand. Microsurgery 2007;27:2-7.

36. Gago LA, Saed GM, Chauhan S, Elhammady EF, Diamond MP. Seprafilm (modified hyaluronic acid and carboxy-methylcellulose) acts as a physical barrier. Fertil Steril 2003;80:6I2-6.

37. Hiro D, Ito A, Matsuta K, Mori Y. Hyaluronic acid is an endogenous inducer of interleukin-I production by human monocytes and rabbit macrophages. Biochem Biophys Res Commun 1986; 140:715-22.

38. Mensitieri M, Ambrosio L, Nicolais L, Bellini D, O’Regan M. Viscoelastic properties modulation of a novel autocrosslinked hyaluronic acid polymer. J Mater Sci Mater Med 1996;7:695-8.

39. Sheldon HK, Gainsbury ML, Cassidy MR, Chu DI, Stucchi AF, Becker JM. A sprayable hyaluronate/carboxymethylcellulose adhesion barrier exhibits regional adhesion reduction efficacy and does not impair intestinal healing. J Gastrointest Surg 2012;16:325-33. 
40. Arakawa T, Timasheff SN. Mechanism of poly (ethylene glycol) interaction with proteins. Biochemistry 1985;24:6756-62.

41. Liu LS, Berg RA. Adhesion barriers of carboxymethylcellulose and polyethylene oxide composite gels. J Biomed Mater Res 2002;63:326-32.

42. Thomsen $L$, Schlur $C$. Incidence of painful neuroma after end-to-end nerve suture wrapped into a collagen conduit. A prospective study of 185 cases. Chir Main 2013;32:335-40.

43. Soltani AM, Allan BJ, Best MJ, Mir HS, Panthaki ZJ. Revision decompression and collagen nerve wrap for recurrent and persistent compression neuropathies of the upper extremity. Ann Plast Surg 2014;72:572-8.

44. Abzug JM, Jacoby SM, Osterman AL. Surgical options for recalcitrant carpal tunnel syndrome with perineural fibrosis. Hand (N Y) 2012;7:23-9.

45. Masaer JR, Tullos JR, Mary ET, Meyer RD. Venous wrapping of nerve to prevent scarring. J Hand Surg 1990;15A: 8I7-8.

46. Sotereanos DG, Giannakopoulos PN, Mitsionis GI, Xu J, Herndon JH. Vein-graft wrapping for the treatment of recurrent compression of the median nerve. Microsurgery 1995; 16:752-6.

47. Alligand-Perrin P, Rabarin F, Jeudy J, Cesari B, Saint-Cast Y, Fouque PA, Raimbeau $G$. Vein conduit associated with microsurgical suture for complete collateral digital nerve severance. Orthop Traumatol Surg Res 201 I;97:SI 6-20.

48. Cramer LM. Local fat coverage for the median nerve. In: Lankford LL, editor. Correspondence Newsletter for Hand Surgery. Chicago, III: ASSH; 1985. p. 35.

49. Rose EH, Norris MS, Kowalski TA, Lucas A, Flegler EJ. Palmaris brevis turnover flap as an adjunct to internal neurolysis of the chronically scarred median nerve in recurrent carpal tunnel syndrome. J Hand Surg Am 199|;|6:|9|-20|.

50. Wulle C. The synovial flap as treatment of the recurrent carpal tunnel syndrome. Hand Clin 1996; 12:379-88.

5I. Becker C, Gilbert A. The cubital flap. Ann Chir Main 1988;7:136-42.

52. Vögelin E, Bignion D, Constantinescu M, Büchler U. Revision surgery after carpal tunnel release using a posterior interosseous artery Island flap. Handchir Mikrochir Plast Chir 2008;40:122-7.

53. Adani R, Tarallo L, Battiston B, Marcoccio I. Management of neuromas in continuity of the median nerve with the pronator quadratus muscle flap. Ann Plast Surg 2002;48:35-40.

54. Goitz RJ, Steichen JB. Microvascular omental transfer for the treatment of severe recurrent median neuritis of the wrist: a long-term follow-up. Plast Reconstr Surg 2005; I 15:163-7I.

55. Huntoon MA, Burgher AH. Ultrasound-guided permanent implantation of peripheral nerve stimulation (PNS) system for neuropathic pain of the extremities: original cases and outcomes. Pain Med 2009;10:1369-77.

56. Deer TR, Levy RM, Rosenfeld EL. Prospective clinical study of a new implantable peripheral nerve stimulation device to treat chronic pain. Clin J Pain 2010;26:359-72.

57. Simpson EL, Duenas A, Holmes MW, Papaioannou D, Chilcott J. Spinal cord stimulation for chronic pain of neuropathic or ischaemic origin: systematic review and economic evaluation. Health Technol Assess 2009; I3:I-I54.

58. Reisman NR, Dellon AL. The abductor digiti minimi muscle flap: a salvage technique for palmar wrist pain. Plast Reconstr Surg 1983;72:859-65.

59. Strickland JW, Idler RS, Lourie GM, Plancher KD. The hypothenar fat pad flap for management of recalcitrant carpal tunnel syndrome. J Hand Surg Am 1996;21:840-8.
60. Rose $\mathrm{EH}$. The use of the palmaris brevis flap in recurrent carpal tunnel syndrome. Hand Clin 1996; 12:389-95.

61. Jones NF. Treatment of chronic pain by "wrapping" intact nerves with pedicle and free flaps. Hand Clin 1996;12:765-72.

62. Giunta R, Frank U, Lanz U. The hypothenar fat-pad flap for reconstructive repair after scarring of the median nerve at the wrist joint. Chir Main 1998; 17:107-12.

63. Frank $U$, Giunta R, Krimmer H, Lanz U. Relocation of the median nerve after scarring along the carpal tunnel with hypothenar fatty tissue flap-plasty. Handchir Mikrochir Plast Chir 1999;31:317-22.

64. Guillemot E, Le Nen D, Colin D, Stindel E, Hu W, L'Heveder G. Perineural fibrosis of the median nerve at the wrist. Treatment by neurolysis and dermal-hypodermal graft. Chir Main 1999;18:279-89.

65. Mathoulin C, Bahm J, Roukoz S. Pedicled hypothenar fat flap for median nerve coverage in recalcitrant carpal tunnel syndrome. Hand Surg 2000;5:33-40.

66. De Smet L, Vandeputte G. Pedicled fat flap coverage of the median nerve after failed carpal tunnel decompression. J Hand Surg Br 2002;27:350-3.

67. Dahlin LB, Lekholm C, Kardum P, Holmberg J. Coverage of the median nerve with free and pedicled flaps for the treatment of recurrent severe carpal tunnel syndrome. Scand J Plast Reconstr Surg Hand Surg 2002;36:172-6.

68. Luchetti R, Riccio M, Papini Zorli I, Fairplay T. Protective coverage of the median nerve using fascial, fasciocutaneous or island flaps. Handchir Mikrochir Plast Chir 2006;38:317-30.

69. Craft RO, Duncan SF, Smith AA. Management of recurrent carpal tunnel syndrome with microneurolysis and the hypothenar fat pad flap. Hand (N Y) 2007;2:85-9.

70. Fusetti C, Garavaglia G, Mathoulin C, Petri JG, Lucchina S. A reliable and simple solution for recalcitrant carpal tunnel syndrome: the hypothenar fat pad flap. Am J Orthop 2009;38:18I-6.

71. Elliot D, Lloyd M, Hazari A, Sauerland S, Anand P. Relief of the pain of neuromas-in-continuity and scarred median and ulnar nerves in the distal forearm and wrist by neurolysis, wrapping in vascularized forearm fascial flaps and adjunctive procedures. J Hand Surg Eur Vol 20I0;35:575-82.

72. Espinoza DP, Kalbermatten DF, Egloff DV, Raffoul W. Neurolysis using a carbohydrate polymer gel for the treatment of postoperative neuropathic pain. Scand J Plast Reconstr Surg Hand Surg 2010;44:12-6.

73. Varitimidis SE, Riano F, Vardakas DG, Sotereanos DG. Recurrent compressive neuropathy of the median nerve at the wrist: treatment with autogenous saphenous veinwrapping. J Hand Surg $B r$ 2000;25:27I-5.

74. Masear VR. Nerve wrapping. Foot Ankle Clin 201 I; 16:327-37.

75. Kokkalis ZT, Jain S, Sotereanos DG. Vein wrapping at cubital tunnel for ulnar nerve problems. J Shoulder Elbow Surg 2010;19:91-7.

76. Vernadakis AJ, Koch H, Mackinnon SE. Management of neuromas. Clin Plast Surg 2003;30:247-68, vii.

How to cite this article: Tos $\mathrm{P}$, Crosio $\mathrm{A}$, Pugliese $\mathrm{P}$, Adani R, Toia F, Artiaco S. Painful scar neuropathy: principles of diagnosis and treatment. Plast Aesthet Res 2015;2:156-64.

Source of Support: Nil, Conflict of Interest: None declared.

Received: 09-12-2014; Accepted: 11-05-2015 